\title{
The Evolving Roles of the Medical Journal
}

\section{Citation}

Podolsky, Scott H., Jeremy A. Greene, and David S. Jones. 2012. The Evolving Roles of the Medical Journal. New England Journal of Medicine 366, no. 16: 1457-1461.

\section{Published Version}

doi:10.1056/NEJMp1113567

\section{Permanent link}

http://nrs.harvard.edu/urn-3:HUL.InstRepos:33750348

\section{Terms of Use}

This article was downloaded from Harvard University's DASH repository, and is made available under the terms and conditions applicable to Other Posted Material, as set forth at http:// nrs.harvard.edu/urn-3:HUL.InstRepos:dash.current.terms-of-use\#LAA

\section{Share Your Story}

The Harvard community has made this article openly available.

Please share how this access benefits you. Submit a story.

\section{Accessibility}




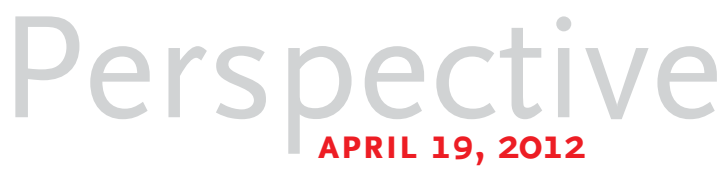

200TH ANNIVERSARY ARTICLE

\section{The Evolving Roles of the Medical Journal}

Scott H. Podolsky, M.D., Jeremy A. Greene, M.D., Ph.D., and David S. Jones, M.D., Ph.D.

\section{A s Chicago physician J.H. Salisbury remarked in 11906, the influence of the medical journal on the life of the physician is unparalleled: "Medical school is attended, as a rule, but once in a lifetime;}

the meetings of the medical society are usually infrequent, but the medical journal, like the newspaper, is an ever-present friend whose influence and advice are potent for good or evil." ${ }^{\text {Y }}$ Yet medical journals have often had a tenuous existence. Thousands have come and gone over the past 200 years, and many continue to struggle to define their role.

The New England Journal of Medicine has persisted, and its history provides a window on the changing functions of both medical journals and the medical profession. Journals don't simply disseminate new knowledge about medical theory and practice. They also define the scope of medical concerns and articulate norms for physicians' professional and social roles. Simultaneously, they work to preserve their reputation, finan- cial stability, and editorial independence in a constantly changing publishing environment, amid an avalanche of medical information.

\section{THE ORIGINS AND EPIDEMIOLOGY OF MEDICAL JOURNALS}

Launched in 1812, the New England Journal of Medicine and Surgery and the Collateral Branches of Science was a latecomer to medical publishing in the new republic: medical journals had already been established in New York, Philadelphia, and Baltimore. The first issue included essays on clinical problems, reviews of general progress in the sciences, a celebration of Francois Xavier Bichat, and an account of an effort to decipher a secret French remedy for gout. Initially published quarterly, the Journal merged in 1828 with the Boston Medical Intelligencer to become the weekly Boston Medical and Surgical Journal, a name it kept for a century. Survival was a challenge. As prominent journals struggled and folded during the Civil War, the Journal asked readers for financial support and submissions "which will show that the light of pure medical science still burns among us undimmed by the heavy clouds of national trial and adversity" (1864; see box for cited Journal articles).

Throughout the century, hundreds of new journals appeared, as medical societies, medical colleges, and therapeutic sects planted their flags. In 1879, the same year he established the Index Medicus to tame the growing medical literature, Surgeon General John Shaw Billings complained that "it is as useless to advise a man not to start a new journal as it is to advise him not to commit suicide" (1879a). By 1882, nearly three quarters of the 509 journals founded in the United States since 1797 had reportedly "passed over to the silent land." 2 
Historical Journal Articles Cited.

New England Journal of Medicine and Surgery and the Collateral Branches of Science 1812. Gorham J. Medical report. 1:317-9.

1816. Bigelow J. Some account of the White Mountains of New Hampshire. 5:321-38.

Boston Medical and Surgical Journal

1864. Difficulties of medical journalism in America at the present time. 71:165-6.

1865. Medical journals. 72:362-4.

1876. American medical journalism. 95:472-4.

1877. Homœopathy. 97:164-5.

1879a. Billings JS. The medical journals of the United States. 100:1-14.

1879b. Worthless periodicals. 100:304-5.

1906. Euthanasia — degenerated sympathy. 154:330-1.

1909. Austin CK. The gospel of peace. A vacation in Norway. 161:47-51.

1912a. The ship's doctors of the Titanic. 166:712.

1912b. Mears JE. A further study of the problem of race betterment. 167:455-61.

1913. Blumer $G$. The need of reorganization in the methods and teaching of therapeutics. 169:261-6.

1914. Truth-telling by physicians. 171:240-1.

1923. Case records of the Massachusetts General Hospital. 189:79.

New England Journal of Medicine

1952. Garland J. The New England Journal of Medicine and the Massachusetts Medical Society. 246:801-6.

1957. Garland J. Editorial responsibility for medical advertisements. 257:1117-20.

1966a. Persistent pesticides. 274:50.

1966b. Beecher HK. Ethics and clinical research. 274:1354-60.

1969. Definition of sole contribution. 281:676-7.

1972. Ingelfinger FJ. Purpose of the general medical journal. 287:1043-4.

1977. Ingefinger FJ. Shattuck lecture - The general medical journal: for readers or repositories? 296:1258-64.

1979a. Relman AS. Holistic medicine. 300:312-3.

1979b. Fletcher RH, Fletcher SW. Clinical research in general medical journals: a 30-year perspective. 301:180-3.

1981. Berry EM. The evolution of scientific and medical journals. 305:400-2.

1986. Leaf A. New perspectives on the medical consequences of nuclear war. 315:905-12.

1989. Leaf A. Potential health effects of global climactic and environmental changes. 321:1577-83.

1991. Quill TE. Death and dignity - a case of individualized decision making. 324:691-4.

1992. Bero LA, Galbraith A, Rennie D. The publication of sponsored symposiums in medical journals. 327:1135-40.

1997a. Angell M. The ethics of clinical research in the Third World. 337:847-9.

1997b. Varmus H, Satcher D. Ethical complexities of conducting research in developing countries. 337:1003-5.

1999a. Kassirer JP. Should medical journals try to influence political debates? 340:466-7.

1999b. Kassirer JP. Editorial independence. 340:1671-2.

1999c. Kassirer JP. Goodbye, for now. 341:686-7.

1999d. Angell M. The Journal and its owner — resolving the crisis. 341:752.

2000. Angell M. Is academic medicine for sale? 342:1516-8.

2004. DeAngelis C, Drazen JM, Frizelle FA, et al. Clinical trial registration: a statement from the International Committee of Medical Journal Editors. 351:1250-1.

2006. Shuchman M, Redelmeier DA. Politics and independence - The collapse of the Canadian Medical Association Journal. 354:1337-9.

2007. Gallagher TH, Studdert D, Levinson W. Disclosing harmful medical errors to patients. 356:2713-9.

2008. Steinbrook R. Physician-assisted death — from Oregon to Washington State. 359:2513-5.

Nor did survival ensure quality. According to an 1879 Journal article, the Chicago Medical Journal and Examiner had surveyed the survivors and deemed many "absolutely worthless" and others "undeniably worse than worthless - they are dangerous and disgusting parasites upon the body medical." In 1876, the Journal's editors opined that it "would be an immense gain if the medical journalism of our whole country could be compressed into not more than half a dozen weeklies," plus a few monthlies, quarterlies, and specialty journals. Such dreams of rationalized medical communications yielded to an awareness of the commercial realities of a Dar- winian "struggle for existence" (1913).

Although the Journal endured through the 19th century and beyond, it initially lived in the shadow of the Journal of the American Medical Association (JAMA, founded in 1883), the dominant medical journal in North America well into the 20th century. ${ }^{3}$ Nonetheless, the Journal celebrated its centennial twice, in 1912 and 1928. In 1921, it was sold to the Massachusetts Medical Society for $\$ 1-$ though the purchase provided more stability than the price suggests. Competition remained keen in 1921, with more than 5000 medical journals "descending like locusts on the land" (1952). And it intensified over the century, as general journals begat specialty journals, subspecialty journals, single-subject journals . . . and then, to link them up again, interdisciplinary journals, all of which "were fruitful and multiplied" (1981). Although this journal, renamed the New England Journal of Medicine in 1928, achieved global prominence, its editors remained anxious - in particular, Franz Ingelfinger admitted in 1972, about the role of a general medical journal in a world of subspecialized knowledge and practice.

\section{THE MANY ROLES OF A MEDICAL JOURNAL}

Speaking before the American Association of Medical Editors in 1884, president Leartus Connor defined an ambitious vision for the medical journal. It ought to be a medical school, a residency program, a clinical preceptor, a set of textbooks, and a medical society unto itself. "In short," Connor concluded, "it is the great unifier of the past and present, the diffuser of all new facts, new thoughts, all new and better appliances for the study of the hu- 


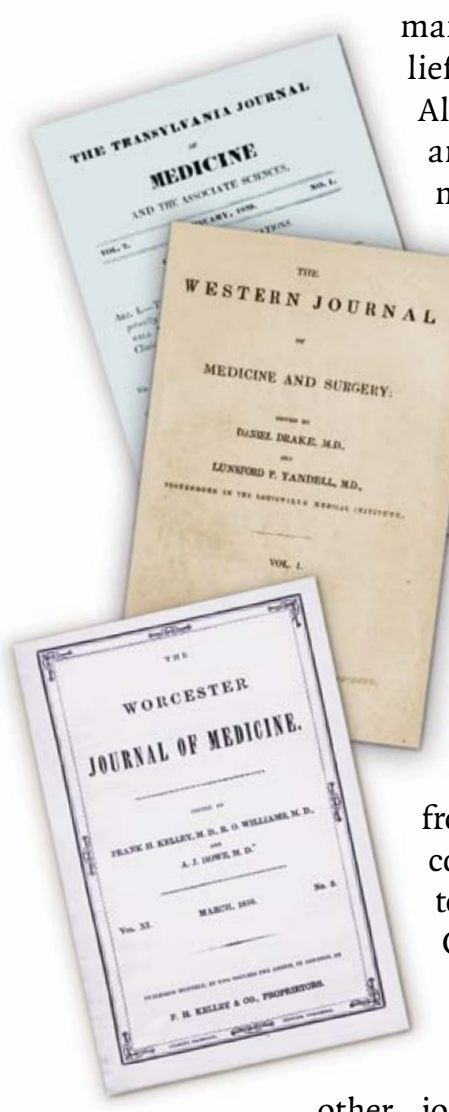

man body and for the relief of its derangements." Although this may seem an impossible mandate, nearly all these goals remain recognizable in journals today. The dissemination by journals of new research results in pathophysiology and therapeutics demonstrates the changing ways in which medical knowledge is produced. In the Journal's early decades, original research contributions from American physicians couldn't fill even a quarterly, according to Joseph Garland (1952). The editors supplemented research with reviews of books, conferences, and other journals and presented French and German scholarship (conducting literally "translational" medicine). They also published reviews of clinical practice, case reports, readers' letters, and their own editorials.

Over the years, journals have not simply responded to submissions, disseminating pieces of knowledge like cargo on a train. They have shaped both the tracks and the trains, using their perspective and authority to articulate and enforce standards for the forms research should take promoting the use of case studies in the early 20th century and lamenting "weak research designs" and the slow adoption of randomized, controlled trials in the late 20th century (1979b). Editors have begun aggressively policing conflicts of interest among researchers (2000) and have banded together to call for transparency in clinical trials, requiring public trial registration as a precondition for consideration for publication (2004).

Journals have also played a more tacit yet crucial role: delineating the appropriate domain of medical knowledge and practice. In choosing which topics to cover, editors make judgments about what doctors and health policymakers ought to know. Reports about botany and natural history, once essential to medical practice, have disappeared, replaced by topics such as epigenetics and pharmacogenomics. Sometimes editors exclude topics. The Journal, for instance, repeatedly refused to grant homeopathy and other therapeutic alternatives the "recognition which would be extended cheerfully to a legitimate enterprise" (1877, 1979a).

More often, they follow medicine far afield, from the climatology data that appeared regularly in 1812, to concerns about degeneracy and race suicide in 1912 (1912b), and exposés on the health effects of environmental hazards (1966a), nuclear war (1986), and global climate change (1989). Joseph Garland, who oversaw the Journal's expansion into an international forum, believed that journals and their editorials need not "necessarily be confined to topics related to medicine, so long as they are ones in which the reader has or might have an interest" (1952). Subsequent editors have concurred, arguing that editorial decisions must "take into account philosophy, politics, economics, pedagogy and other social aspects of health care" (1977) and that medical journals must include "exposure and discussion of important issues that involve, even indirectly, health and medicine" (1999a). This ambition to participate in contemporary social and political debates is reflected in the Journal's engagement with health care reform today.

The Journal's mediation between biomedical science and the social context of health care demonstrates another role of medical journals: their defining of the medical profession as a social and moral community. The Journal's early editors recognized that general medical journals "furnish a bond of union and sympathy between the members of our profession which nothing else can supply" (1865). Journals have provided a forum for community news, announcements, and obituaries of exemplars of professional conduct. Such ephemera often convey important norms for practicing physicians. When the Titanic sank, editorials celebrated the ship's surgeons, who died at their posts: "The heroism of these two physicians, though no more than their recognized duty, is worthy cause for gratitude and gratification to the profession whose representatives they were and to whose ideals they were so loyally true" (1912a).

Sometimes the Journal published travelogues, from Jacob Bigelow's ascent of Mount Washington in 1816 to Cecil Austin's Norwegian vacations in 1909. Such accounts stressed that doctors,

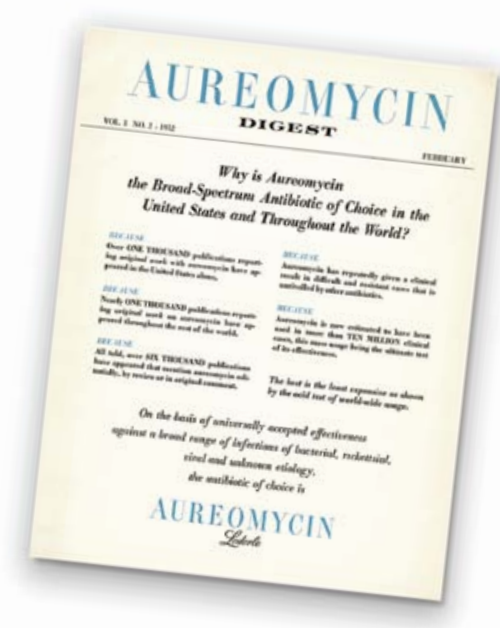




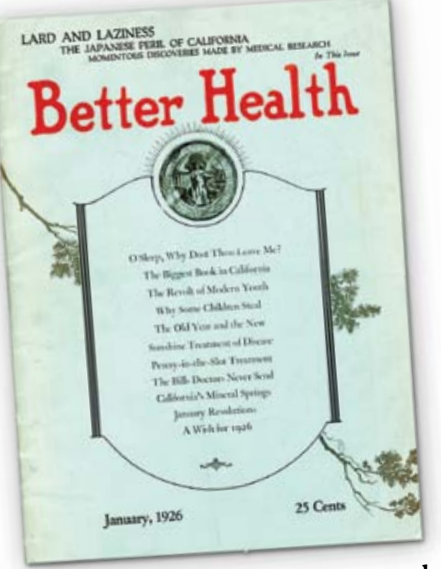

even at leisure, were men of science, attentive to the geology, botany, zoology, and anthropology of places they visited. Vestiges of this genre can be seen in the photographs by physicians published today. Though used primarily "to fill otherwise empty space" (1999c), they reflect the identities and aspirations of a community of readers. When taken by physicians living in distant locales, they also reflect the globalization of the Journal and medical science.

Medical journals have occasionally explicitly focused on community norms. The Journal has famously taken stands on research ethics, from Henry Beecher's influential 1966 exposé of unethical research (1966b) to debates about standards for conducting clinical trials in developing countries (1997a, 1997b). Journals have also addressed the changing ethics of clinical practice. The Journal published a 1906 plea to reconsider reflexive prohibitions against euthanasia, Timothy Quill's moving 1991 account of his decision to assist in the suicide of a patient dying from leukemia, and continuing coverage of debates about physicianassisted death (2008). It has provided a forum for debates about the merits of truth telling and withholding information from patients, whether in cases of medical uncertainty (1914) or medical error (2007). Indeed, the moral responsibility to discuss errors within the medical community - motivated the 1923 decision to publish the Case Records of the Massachusetts General Hospital. These were presented in part to provide "comfort" to physicians struggling in isolation with difficult cases. "Harbors are made safer for mariners not by records of prosperous voyages," a 1923 editorial noted, "but by buoying the dangerous reefs and sunken ledges that have caused disasters. If for nothing else, these Case Records are of exceptional value because of their honest acknowledgment of mistakes."

\section{CHALLENGES THEN AND NOW}

To survive, medical journals have relied on sponsors (medical societies or colleges) and advertisers (pharmaceutical and otherwise), forming relationships sometimes seen as Faustian bargains. Although medical society sponsorship might seem benign, editors have often bridled at compromising their autonomy. In 1884, Connor dreamed of a time when journals could be free from sponsors who "cripple their perfect independence to work, and think, and speak for the great masses of the medical profession." ${ }^{2}$ Yet many prominent medical journals remain under the control of medical societies. In the past 15 years, tensions between editors and overseers have been implicated in editorial turnover at JAMA (1999b), the New England Journal of Medicine (1999d), and the Canadian Medical Association Journal (2006).

The relationship with advertisers has been no easier. Connor decried the "prostitution of the reading pages to the supposed interests of the advertising columns."2 Garland, in 1957, lamented that the medical journal remained dangerously dependent on pharmaceutical advertisements for its financial lifeblood. Nevertheless, Garland understood that the problem could not be resolved by abstinence: "We as physicians recognize and appreciate our ancient partnership and our friendly relations with our dynamic friends, the manufacturing apothecaries." He continued, more pointedly, that "as editors we delight in the revenue from their adventures in competitive advertising, even as we seek to put restraints on its ultrapersuasiveness and keep it within the bounds that medical propriety and a sense of service to humanity have set." Yet constant vigilance has been required to maintain firewalls between promotion and education (1992).

Even when survival seemed sure, journals have struggled to make themselves heard amid the competing literature. Ever since Billings assembled the Index Medicus, writers have used the language of pathology to critique the vastness of the journal literature. Even before medical research dramatically expanded after World War II, the Lancet reported in 1935 on the growing "journalistic blastoma." Four years later, Sir Robert Hutchinson described the "enormous proliferation, this pullulating fungus-like growth," that threatened

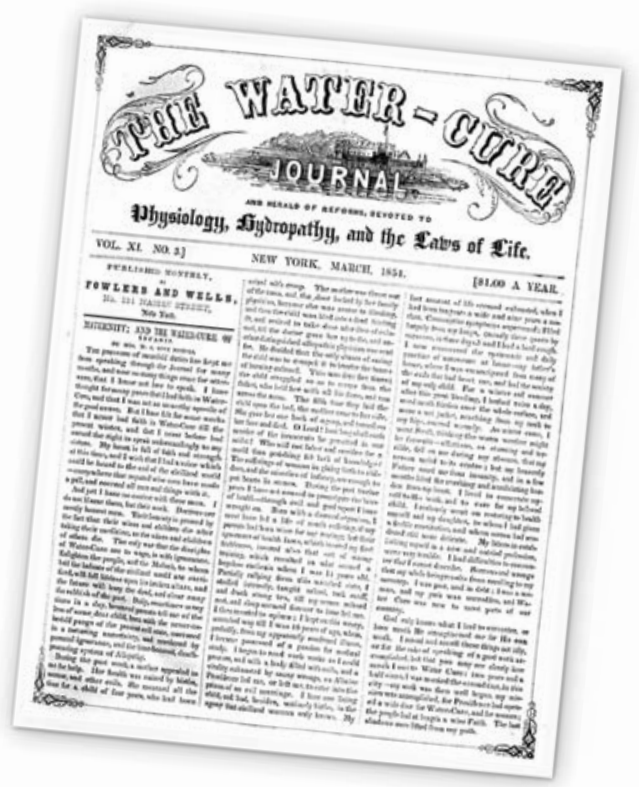


the medical community's vitality. Rather than "see science suffocated in its own secretions," Hutchinson prescribed journalistic "birth control." 4 Journals remained nonadherent.

By the late 20th century, journals needed to compete not just with each other but with newspapers and other media. As Franz Ingelfinger noted in 1977, "Medicine has become the stuff of headlines." New topics drew further attention to medical journals -

\section{PHOTOGRAPHIC REVIRIN}

MEDICINE AND SURGERT

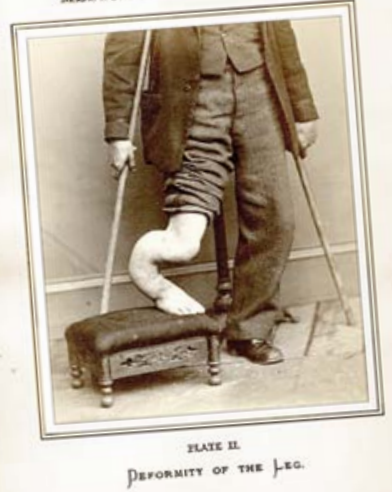

debates about health policy and national medical insurance, malpractice, specialinterest lobbying regarding particular diseases, and interest in health education. The growing market in medical news attuned journal editors to their content's "newsworthiness." In 1969, the Journal articulated this relationship in its Ingelfinger Rule, a policy against publishing anything that had already appeared elsewhere. Other journals followed suit. This rule, combined with embargo policies, has led to a carefully choreographed production in which medical journals and the popular press work cooperatively and competitively to influence the news cycle.

New media, too, have presented challenges. In the 1960 s, the National Institutes of Health (NIH) experimented with Information Exchange Groups, letting scientists communicate directly with one another by sending mimeographs to colleagues. ${ }^{5}$ From a group of 32 membrane-biology researchers in 1961, the program expanded to 3600 members 5 years later. Many saw in this mechanism the inevitable demise of medical journals. A former Lancet editor predicted, "A day will come when journals will be superseded as a means of publishing new research." But the NIH closed the program in 1966, owing to insufficient funds for mimeographs and mailings and concerns about the absence of refereeing and excessive emphasis on priority.

The Internet and other social media technologies have enabled new experiments. Open-access journals shift publication costs to authors so that research results may be freely shared globally. Blogs, listserves, and Twitter feeds permit everyone an authorial voice and increasingly influence what counts as relevant medical information. Journalists and bloggers routinely cover major medical conferences, broadcasting promising discoveries before research has been submitted for peer review and publication. Many of these journal-bypassing models assert a morality that contrasts the virtues of open access with the centralized power and profits of traditional publishers. The optimal role of the medical journal in this environment remains undetermined.

\section{THE FUTURE}

For two centuries, medical journals have mediated the production and dissemination of medical knowledge, their histories inextricably entwined with that of the medical system. Despite the emergence of rivals that were unimaginable a generation ago, the Journal and its peers maintain substantial influence on both the medical profession and society. But anxiety remains: What does the future hold?

Navigating many obstacles, medical journals have persisted, adapting to changing environments and embracing new opportunities. Elaborate websites now offer Web-only content, including audio, video, and other once-impossible formats. Journals must continue to manage not just the shifting landscape of the production and publishing of medical knowledge, but also the broader currents of their social, economic, and political contexts. This responsibility cannot be borne by editors alone. Readers' decisions - which subscriptions they keep, which free content they browse - will shape the decisions of journal editors, sponsors, and advertisers. Priorities and prospects for journals in the future depend on how, and how well, physicians use them today.

Disclosure forms provided by the authors are available with the full text of this article at NEJM.org.

From the Department of Global Health and Social Medicine, Harvard Medical School (S.H.P., J.A.G., D.S.J.); the Center for the History of Medicine, Countway Library of Medicine (S.H.P.); and the Division of Pharmacoepidemiology and Pharmacoeconomics, Brigham and Women's Hospital (J.A.G.) - all in Boston; and the Department of the History of Science, Harvard University, Cambridge, MA (J.A.G., D.S.J.)

1. Salisbury JH. The subordination of medical journals to proprietary interests. JAMA 1906;46:1337-8.

2. Connor L. The American medical journal of the future as indicated by the history of American journals in the past. JAMA 1884;2:650-7.

3. Knoll E. The American Medical Association and its journal. In: Bynum WF, Lock S, Porter R. Medical journals and medical knowledge: historical essays. London: Routledge, 1992:146-59.

4. Hutchinson R. Medical literature. Lancet 1939;2:1059-62.

5. Abelson $\mathrm{PH}$. Information exchange groups. Science 1966;154:727.

6. Fox T. Crisis in communication: the functions and future of medical journals. London: Athlone Press, 1965.

Copyright $(\odot 2012$ Massachusetts Medical Society. 